\title{
Effect of Annealed Si/Ti/Pt Hetero Structure on The Response Time and Signals of Hydrogen Sensors
}

\author{
Wahyu Widanarto $^{1}$, Farzand Abdullatif ${ }^{1}$, Christoph Senft ${ }^{2}$, and Walter Hansch ${ }^{2}$ \\ ${ }^{1}$ Department of Physics, Jenderal Soedirman University, \\ Jl. Dr. Soeparno 61,53123 Purwokerto, Indonesia \\ ${ }^{2}$ Institut für Physik, Universität der Bundeswehr München, \\ Werner-Heisenberg-Weg 39, 85579 Neubiberg, Germany \\ e-mail: wahyu.widanarto@gmail.com
}

Received 30 December 2010, Revised 12 December, Accepted 23 December 2010

\begin{abstract}
Titanium (Ti) and platinum (Pt) films deposited on p-doped Si electrode were incorporated as gas sensitive electrodes in Kelvin and Floating Gate Field Effect Transistor (FG-FET) systems. The films were annealed in oxygen at $800^{\circ} \mathrm{C}$. SEM and EDX characterization methods were employed to study the surface of these films. Work function changes with respect to various hydrogen concentrations have been measured as a function of temperature and humidity. The results show that nano grains of titanium silicide (TiSi $\left.{ }_{2}\right)$ and Pt islands are formed after the annealing. Annealed TiSi $2 / \mathrm{Pt}$ films are well suitable to significantly stabilize FG-FET based hydrogen sensor. The sensors can detect $\mathrm{H}_{2}$ in concentration range between $0.3 \%$ and $2 \%$ from room temperature up to $135^{\circ} \mathrm{C}$. The response time is quite fast i.e. $t_{90} \sim 43.2$ seconds. An experiment on the stability has proved that signal pattern of the sensors remained stable one month after first conditioning.
\end{abstract}

\section{Keywords: Hydrogen Sensor, Floating Gate Field Effect Transistor (FG-FET), Titanium Silicide (TiSi 2 ), Platinum}

\section{Introduction}

Hydrogen $\left(\mathrm{H}_{2}\right)$ is predicted to be an alternative energy carrier in the future. It will be used in automotive industry and in local fuel cells. It can decrease the problem related to the green house warming by $\mathrm{CO}_{2}$. On the other hand, hydrogen is dangerous due to its explosive character. Already a concentration of $4 \%$ can cause an explosion ${ }^{11}$.

Platinum is known as a chemical sensitive layer for hydrogen detection with the work function principle ${ }^{2)}$. Unfortunately, it has poor selectivity at room temperature ${ }^{3)}$ and will be unstable with increasing operating temperature above $60^{\circ} \mathrm{C}^{1)}$. Huge efforts have been carried out to stabilize it by modifications. It has been reported also that the stability of FET based hydrogen sensor at high temperature can be improved with coating new material film of $\mathrm{Pt} / \mathrm{SnO}_{2}$ on the Pt surface ${ }^{3)}$. However, it should be noted that the response time decreases with increasing thickness of the $\mathrm{SnO}_{2}$ film ${ }^{4}$. To overcome the problem, in this work the $\mathrm{SnO}_{2}$ film is not used and is replaced by annealing the film. Therefore, the sensitivity and stability of $\mathrm{H}_{2}$ detection is enhanced at higher temperatures without decreasing the response time.

In this measurement concept, a Kelvin System and a Floating Gate Field Effect Transistor (FG-FET) are used as transducer to measure work function change $\Delta \Phi$ of gas sensitive films, and convert it into an electrical signal ${ }^{5}$. An interesting advantage of this method is its sensitivity to physisorption as well as chemisorption, which are occurred at surface of the film. Moreover, it can be operated at low temperature, which is an advantage to mobile systems ${ }^{6)}$.

\section{Experimental}

\subsection{Preparation of the Ti/Pt films}

FG-FET sensor system consists of a top electrode and FG-FET chip ${ }^{3,7)}$. The electrodes have been made out of $\mathrm{p}$-doped silicon. In order to detect hydrogen, $110.6 \mathrm{~nm}$ titanium (Ti) and $249.4 \mathrm{~nm}$ platinum (Pt) films were deposited by DC sputtering on the electrodes sequentially. The thickness of the layers is only limited by the dimension of the FG-FET sensor system and does not affect the performance. This is true due to the fact that sensing mechanism of the sensor is only on the surface of the film. Afterwards the electrodes were annealed using horizontal furnace (Carbolite) in oxygen flow of 600 $\mathrm{cm}^{3} / \mathrm{min}$. In the annealing, the temperature was ramped up to $800^{\circ} \mathrm{C}$ at rate of $20^{\circ} \mathrm{C} / \mathrm{min}$, and then it was dwelled for $30 \mathrm{~min}$. Finally, it was ramped down to ambient temperature at rate of $20^{\circ} \mathrm{C} / \mathrm{min}$. Cross section of the film after and before the annealing can be seen in Fig. 1. It can be observed that border between $\mathrm{Si}, \mathrm{Ti}$ and $\mathrm{Pt}$ is very clear before the annealing, meanwhile the border can not be seen anymore after the annealing. It is predicted that the $\mathrm{Si}$, Ti and Pt films were melted to build an alloy. 

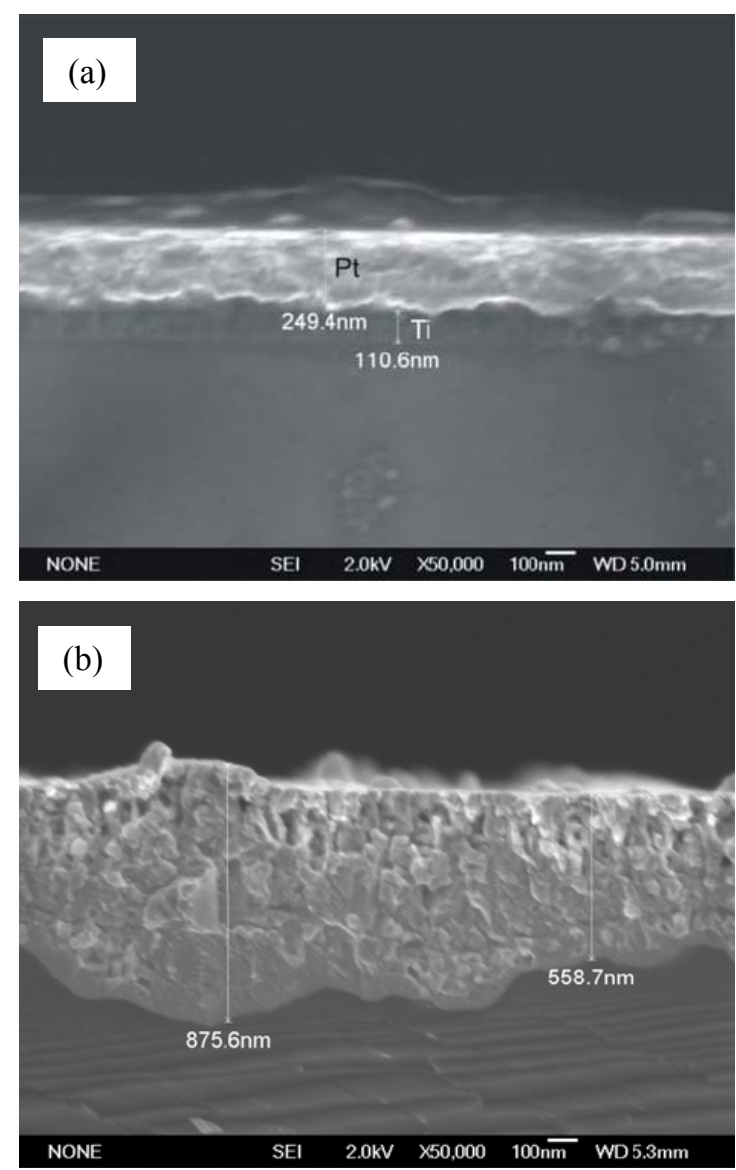

Figure 1. SEM image: Cross section of Ti/Pt film (a) before annealing and (b) after annealing.

\subsection{Surface characterization}

Surface morphology of the films was characterized by Scanning Electron Microscope (SEM). Before the annealing, surface of the film is dense ${ }^{1)}$. After the annealing, nano grains of $\mathrm{TiSi}_{2}$ and $\mathrm{Pt}$ islands are formed on the surface. The surface structure can be seen in Fig.2. This structure is expected to support spill over effect on the surface due to interaction between oxygen and hydrogen molecules. Pt and $\mathrm{TiSi}_{2}$ will be a catalyst and a support material, respectively.

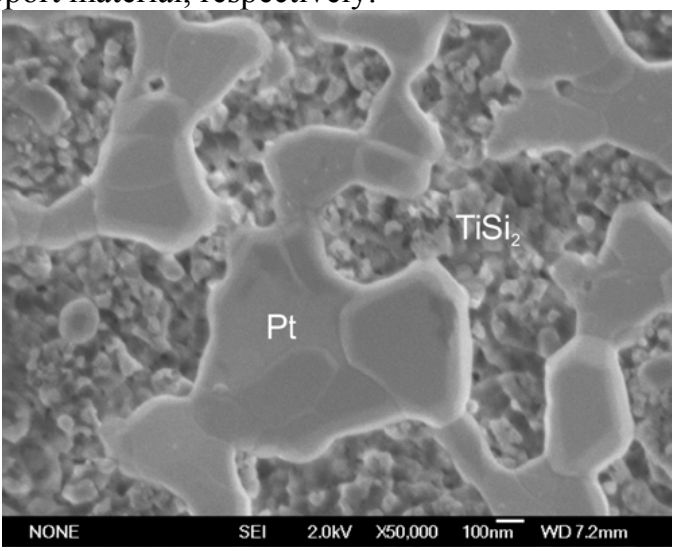

Figure 2. SEM image of the $\mathrm{Ti} / \mathrm{Pt}$ surface after annealing in oxygen at $800^{\circ} \mathrm{C}$.
Characterization of the films was also carried out using Energy-Dispersive X-Ray (EDX) to determine qualitative composition of the surface (see Fig. 3). In the resulting energy spectrum, $\mathrm{Si}$ and $\mathrm{Ti}$ can be observed besides Pt. This is a proof for forming $\mathrm{TiSi}_{2}$ on the surface. Ti and $\mathrm{Si}$ do not react with the ambient oxygen because they are covered by Pt film. It is evident from the EDX pattern that $\mathrm{O}$ is significantly low in quantity after annealing.

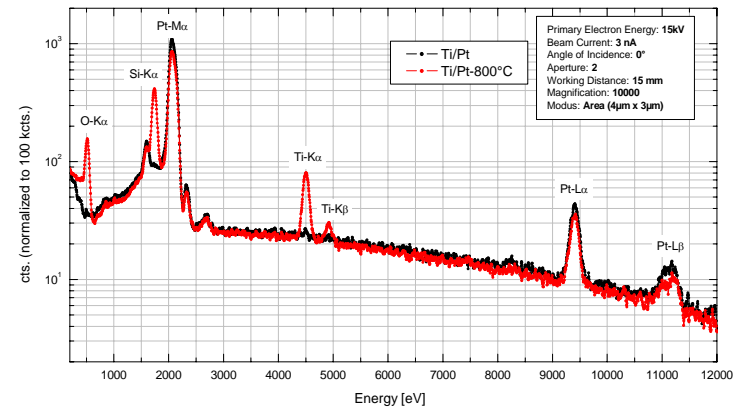

Figure 3. EDX measurement of the Ti/Pt surface before and after annealing in oxygen at $800^{\circ} \mathrm{C}$.

\section{Work Function Change Measurement}

\subsection{Kelvin System}

For the measurement in the Kelvin System (Besocke Delta Phi $\mathrm{GmbH}$ ) related to the experimental FG-FET structure with gas sensitive film was driven the following attempt profile: After stabilization of the operating temperature of $100^{\circ} \mathrm{C}$ and $115^{\circ} \mathrm{C}$, the measurement chambers are rinsed for $15 \mathrm{~min}$ with $100 \mathrm{ml} / \mathrm{min}$ synthetic air. Afterwards, $\mathrm{H}_{2}$ gas with various concentrations is serially exposed to the film for total time of 2.25 hours. The gas is exposed for $15 \mathrm{~min}$. The chambers are rinsed again with the synthetic air for $15 \mathrm{~min}$. The result shows that the film reacts to $\mathrm{H}_{2}$ concentrations as which can be seen in Fig. 4. The reversible and stable work function change $\Delta \Phi$ can be observed during measurement at the both temperatures. Work function change of the films decreases with increasing $\mathrm{H}_{2}$ concentrations. Accordingly, the film will be applied as a $\mathrm{H}_{2}$ sensitive film in the experimental FG-FET sensor system.

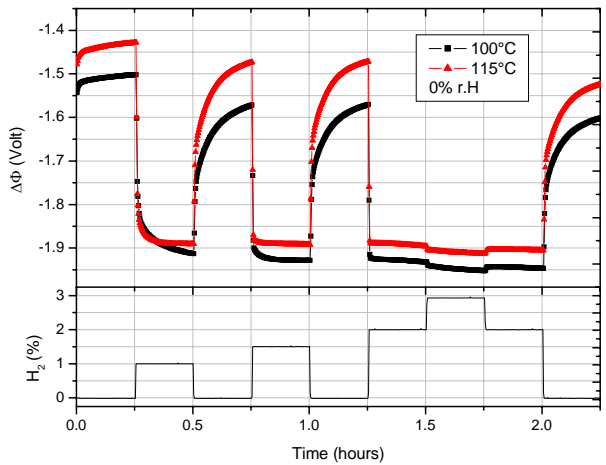

Figure 4. Work function change of the $\mathrm{TiSi}_{2} / \mathrm{Pt}$ film to various $\mathrm{H}_{2}$ concentrations in the Kelvin probe system at $100,115^{\circ} \mathrm{C}$ and dry conditions. 


\subsection{FG-FET Sensor System}

In the experimental FG-FET sensor system, the annealed electrode is mounted on a FG-FET chip to build a hydrogen sensor. In order to know ability of the sensor in hydrogen detection, several tests were carried out.

\section{Temperature Effect on The $\mathrm{TiSi}_{2} / \mathrm{Pt}$ Sensor}

The temperature of the sensor is one of the most important parameters, because adsorption and desoreption are temperature activated processes ${ }^{8}$. Increasing the temperature improves the sensor's sensitivity to test gases. On the other hand, the temperature has an effect on the physical properties of the film which is used in the sensor. An experiment related to temperature effect on $\mathrm{TiSi}_{2} / \mathrm{Pt}$ based the FGFET sensor system was carried out. The sensor is exposed to $1 \%$ of $\mathrm{H}_{2}$ for 15 minutes and rinsed with synthetic air for 15 minutes under dry condition. Operating temperature is varied from room temperature until $165^{\circ} \mathrm{C}$. It can be seen from Fig. 5 that a significant temperature effect on the sensor is observed from room temperature until $135^{\circ} \mathrm{C}$. The sensor signal drops if $\mathrm{H}_{2}$ is present and returns closely to its initial state when $\mathrm{H}_{2}$ disappears. It takes more than 15 minutes for the signal to achieve its stable state. However, a difference in the signal before and after the exposure of $\mathrm{H}_{2}$ becomes noticeable when the temperature is increased. The difference is clearly visible when the temperature is above $135^{\circ} \mathrm{C}$.

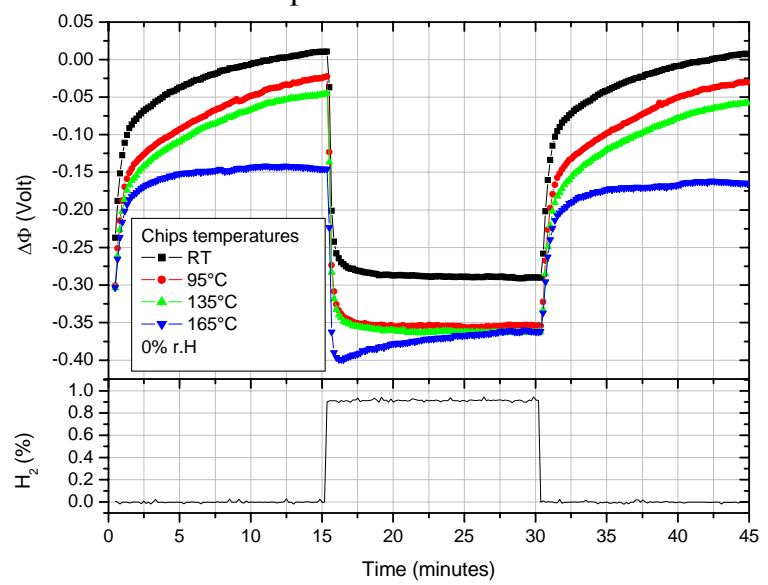

Figure 5. Temperature effect on the $\mathrm{TiSi}_{2} / \mathrm{Pt}$ sensor under dry conditions.

\section{Concentration Dependence of the $\mathrm{TiSi}_{2} / \mathrm{Pt}$ Sensor}

The response of the sensor to various hydrogen concentrations was investigated at the operating temperature of $95^{\circ} \mathrm{C}$ under dry conditions. In multiple steps the sensor is exposed to various hydrogen concentrations for 15 minutes with 15 minutes recovery time between each step. According to Fig. 6, the sensor signal decreases with increasing $\mathrm{H}_{2}$ concentrations. It can detect very well in $\mathrm{H}_{2}$ concentration range between $0.3 \%$ and $2 \%$. At higher concentrations above $0.7 \%$, the signal quickly achieves a steady state. Compared to the Ti/Pt sensor, sensitivity and stability of the $\mathrm{TiSi}_{2}$ sensor is better.
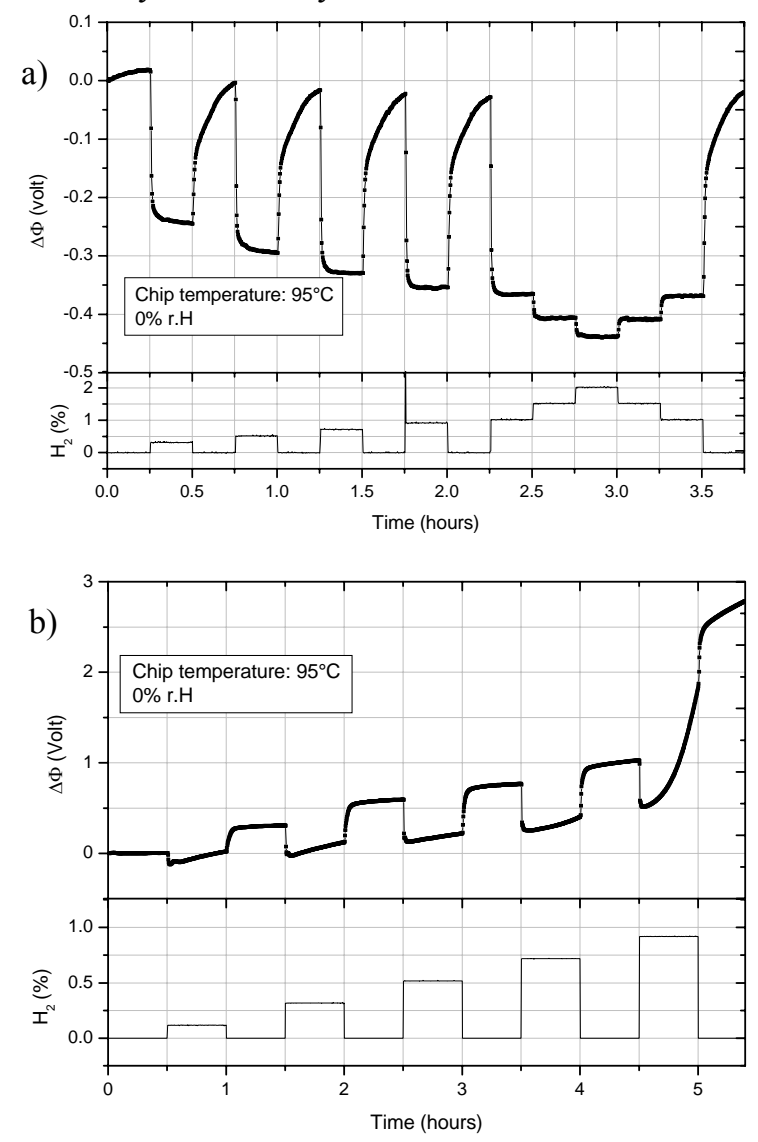

Figure 6. (a) Response of the $\mathrm{TiSi}_{2} / \mathrm{Pt}$ sensor to various $\mathrm{H}_{2}$ concentrations at $95{ }^{\circ} \mathrm{C}$ under dry conditions (b) Response of the $\mathrm{Ti} / \mathrm{Pt}$ sensor to various $\mathrm{H}_{2}$ concentrations at $95{ }^{\circ} \mathrm{C}$ under dry conditions.

\section{Reproducibility of $\mathrm{The} \mathrm{TiSi}_{2} / \mathrm{Pt}$ Sensor}

The reproducibility is one important criterion that determines the ability of the sensor. Regarding the stability of the sensor, an experiment was undertaken at which a sample was tested one month after the first exposure to hydrogen. Here the measurement conditions were room temperature and dry conditions. Fig. 7a proves that the sensor signals remain stable to $1 \%$ of $\mathrm{H}_{2}$ gas exposure with response time $t_{90} \sim 43.2$ second. $t_{90}$ is time, which is needed to reach $90 \%$ of maximum output signal as shown in Fig $7 \mathrm{~b}$. The reproducibility of the output signals is very well. No noticeable signal drifts can be observed after eight times of $\mathrm{H}_{2}$ exposure cycles. 


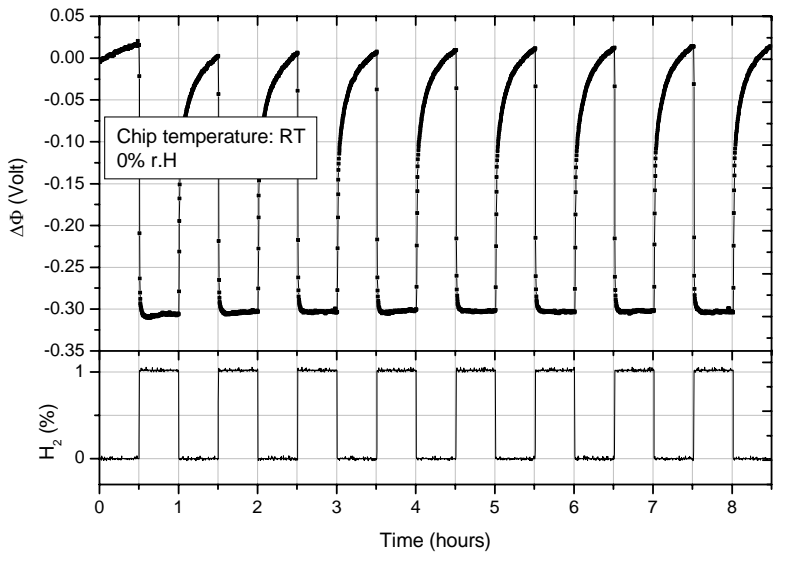

(a)

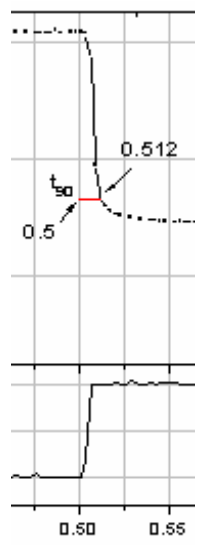

(b)

Figure 7. (a) Stability and reproducibility of the $\mathrm{TiSi}_{2} / \mathrm{Pt}$ sensor toward $1 \%$ of $\mathrm{H}_{2}$ exposure one month without testing after first conditioning at room temperature under dry conditions (b) Response time $t_{90}$.

\section{Longterm Stability of The $\mathrm{TiSi}_{2} / \mathrm{Pt}$ Sensor}

Longterm stability of the sensor was investigated at $60^{\circ} \mathrm{C}$ under $30 \%$ relative humidity after six days without testing. The sensor is exposed to constant flow of dry synthetic air for 15 minutes with interrupted $0.5 \%, 1 \%$ and $2 \%$ of $\mathrm{H}_{2}$ for 15 minutes. Afterwards it is rinsed with synthetic air for 24 hours. This cycle is repeated. Fig. 8 shows the long-term stability of the sensor. The signal pattern and the base line of the sensor still remain stable in the beginning of the measurement after six days without testing. The signals need more than 15 minutes to achieve real base line of the sensor.

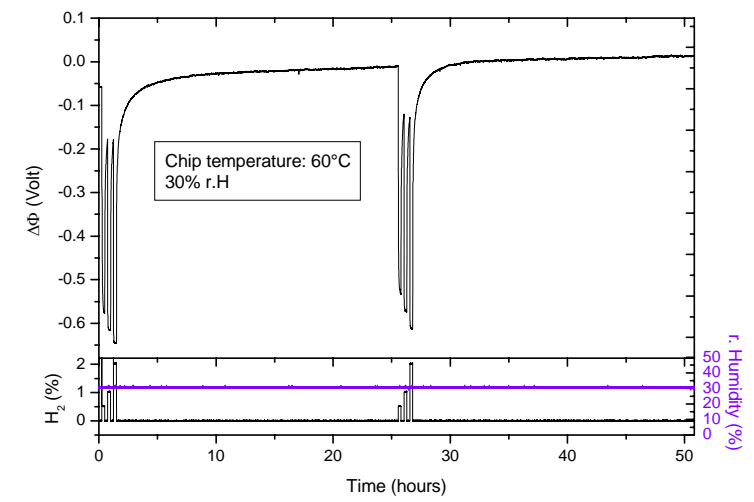

Figure 8. Longterm stability of the $\mathrm{TiSi}_{2} / \mathrm{Pt}$ sensor to $\mathrm{H}_{2}$ at $60^{\circ} \mathrm{C}$ under $30 \%$ relative humidity after six days without testing.

\section{Humidity Effect on The $\mathrm{TiSi}_{2} / \mathrm{Pt}$ Sensor}

From Fig. 9, it can be seen that $\Delta \Phi$ decreases with increasing relative humidity at each $0.9 \% \mathrm{H}_{2}$ concentration. In humid condition, water vapour will cover up the $\mathrm{TiSi}_{2}$ surface, so function of $\mathrm{TiSi}_{2}$ as the support material is not working. As consequently, only few oxygen species is absorbed at the $\mathrm{TiSi}_{2}$ surface. The water vapour will draw $\mathrm{H}^{+}$and $\mathrm{O}^{-}$ions to form synthetic water at the $\mathrm{TiSi}_{2}$ surface. However, it should be noted that hydrogen detection with the sensor is still possible.

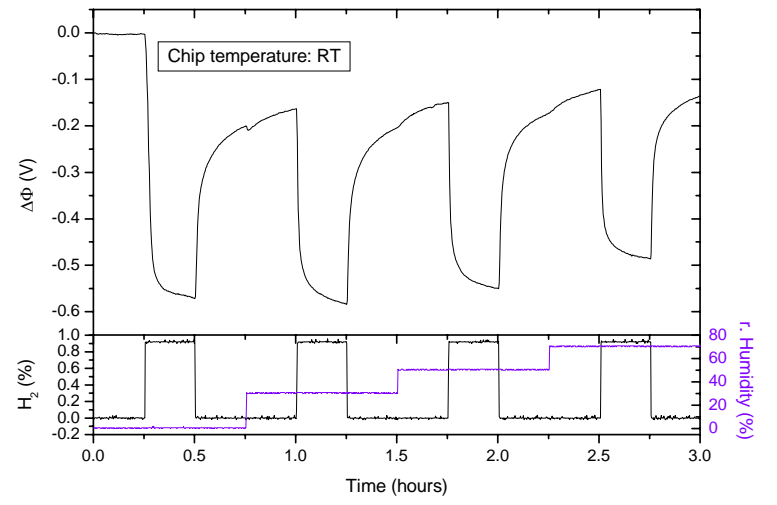

Figure 9. Humidity effect of the $\mathrm{TiSi}_{2} / \mathrm{Pt}$ sensor at room temperature.

\subsection{Model of Gas Sensing Mechanism}

The gas sensing mechanism is based on the spill-over effect due to the presence of dispersed metallic catalyst. If the sensors are exposed to synthetic air $\left(20 \% \mathrm{O}_{2}\right.$ and $\left.80 \% \mathrm{~N}_{2}\right)$, the Pt catalyst dissociates directly $\mathrm{O}_{2}$ molecule into $\mathrm{O}^{-}$atom species. These species spill over onto $\mathrm{TiSi}_{2}$. This causes a broadening of depletion layer at the conduction band near the surface of $\mathrm{TiSi}_{2}$. As a result, the work function of $\mathrm{TiSi}_{2}$ increases. Pt catalyst also dissociates directly $\mathrm{H}_{2}$ molecule into $\mathrm{H}^{+}$atoms, when the sensors are exposed to a mixture from $\mathrm{H}_{2}$ and synthetic air. These atoms spill over onto $\mathrm{TiSi}_{2}$ and react there with the $\mathrm{O}^{-}$atom species. Adsorbed hydrogen atoms act as donors, which provide additional free electrons and induce an electron accumulation layer. As a result work function of $\mathrm{TiSi}_{2}$ decreases leading to a decreasing sensor signal. The reaction scheme is as follow ${ }^{9)}$ :

$$
\begin{aligned}
& \mathrm{O}_{2}+2 \mathrm{Pt} \Leftrightarrow 2 \mathrm{Pt}-\mathrm{O}^{-} \\
& \mathrm{H}_{2}+2 \mathrm{Pt} \Leftrightarrow 2 \mathrm{Pt}-\mathrm{H}^{+} \\
& \mathrm{Pt}-\mathrm{O}^{-}+2 \mathrm{Pt}-\mathrm{H}^{+} \Leftrightarrow 3 \mathrm{Pt}+\mathrm{H}_{2} \mathrm{O}
\end{aligned}
$$




\section{Conclusion}

In summary one can conclude that hetero structure of $\mathrm{Ti} / \mathrm{Pt}$ annealed at $800^{\circ} \mathrm{C}$ is suited to significantly stabilize FG-FET based hydrogen sensor. The sensor can detect $\mathrm{H}_{2}$ in concentration range between $0.3 \%$ and $2 \%$. The sensor offers high sensitivity, reproducibility, longterm stability and negligible base line change at a temperature range from room temperature to $135^{\circ} \mathrm{C}$ under dry and wet conditions with response time ( $t_{90} \sim 43.2$ second). Furthermore, the sensor is more stable with increasing temperatures compared to $\mathrm{Ti} / \mathrm{Pt}$ based hydrogen sensor. The annealing temperature and time will affect the performance and morphology of the film. This effect will be discussed in a separate paper.

\section{Acknowledgements}

This work has been supported by a grant from Directorate General of Higher Education (DGHE) of Indonesia.

\section{References}

1. C. Senft, Austrittsarbeitsbasierte Wasserstoffdetektion für Fahrzeuge mit Brennstoffzellenantrieb. Göttingen, Cuvillier Verlag, 2009.

2. M. Zimmer, Mikrosensoren auf Transistor-Basis zur Wasserstoff- und Ozondetektion. Munich, PhD thesis UniBW, 2003.

3. W. Widanarto, Gas Detection With Floating Gate Field Effect Transistor (FG-FET). Göttingen: Cuvillier Verlag, 2007.

4. T. Galonska, W. Widanarto, and I. Eisele. Cross Sensitivity of FET - Based Hydrogen Sensors, Atlanta 2007.

5. M. Burgmair, Einsatz von Metalloxiden in Gas Sensor, Munich: PhD thesis UniBw, 2003.

6. I. Eisele, Low Power Gas Detection with FET Sensors, Sensors and Actuators, B78, 19, 2001.

7. M. Burgmair, Field Effect Tranduscers for Work Function gas Measurements: Device Improvements and Comparison of Performance, Sensors and Actuators, B95, 183, 2003.

8. S.R. Morrison, The Chemical Physics of Surfaces, Plenum Press, New York, 1977.

9. M. Sze. Semiconductor Sensors, John Wiley \& Sons, Inc., Canada, 1994. 